Journal of Social Sciences 5(2): 80-84, 2009

ISSN 1549-3652

(C) 2009 Science Publications

\title{
Sustainable Regional Development
}

\author{
Helen Theodoropoulou, Roido Mitoula and Malvina Vamvakari \\ Department of Home Economics and Ecology, \\ Harokopio University, 70 E. Venizelos, 17671 Athens, Greece
}

\begin{abstract}
Problem statement: Demographic changes have increased the social and cultural diversity of tourist areas with historical heritage and natural beauty in Greece, causing an expansion in the cultural and economic horizons of local people and producing at the same time conflicts in their interests, values and lifestyles. This research was focused in the concept of sustainable development in three areas in south Greece, in order to examine if tourist development can cause a danger for human values and natural environment. Approach: Three municipalities of southern Peloponnese in Greece namely Koroni, Methoni and Pilos were selected for the study. These three municipalities were selected because they constitute regions of common historical heritage, big natural beauty and high environmental importance. By using empirical social research methods, sample data of 120 questionnaires were collected on the characteristics of residents and local enterprises and land use changes in these areas. Results: The main employment is farming (24\%), even though that residential land had increased at the expense of farmland. Local residents in the public or private sector supplement their low income with agricultural or tourist activities $(67 \%)$. Therefore, new enterprises were found through private investments, which increase the local entrepreneurship (42\%). In addition, the analysis of the multiple regression models showed that local development increases in places with more chances for employment. Also, among areas with the same cultural development those with better infrastructure were expected to have more sustainable development (6 units of difference) than those areas with worse infrastructure. Conclusion: Development of soft tourism, organic farming and better infrastructure could enhance sustainable development in tourist areas with historical heritage, big natural beauty and high environmental importance.
\end{abstract}

Key words: Sustainable, regional development, local development

\section{INTRODUCTION}

The internationalization of markets and the socioeconomic realignments of globalization influence the productive activities of Greece. These developments create particular difficulties of adaptation in small, traditional economies of rural regions in Greece. On one hand "the new order" that creates the globalization and on the other hand the slow processes of reformation and import of new technologies in combination with the lack of basic infrastructures, make visible the dangers of weakening the economy and social web in these regions ${ }^{[1-4]}$. Therefore, rural regions in order to avoid depopulation and to accomplish local development, they are focused in the exploitation of particular regional advantages and capabilities and their residents for the creation of opportunities of employment and the maintenance of places of work ${ }^{[2,3]}$. Successful policies of regional development aim in the mobilization of local forces and in the attendance of residents in the publics in a sustainable way ${ }^{[4-9]}$.
In order to evaluate the regional development of small, traditional economies of rural regions in Greece from the social-economic point of view, three municipalities of southern Peloponnese were examined with the aim to record their adaptation in the requirements of reformation of economy and globalization of markets. All three municipalities are old cities with old civilisation, but now are affected significantly by social and economic changes, because of the increase of tourism. The economy of those areas is becoming more diversified as the service sector grows significantly at the expense of other sectors, like agriculture. Demographic changes has increased the social and cultural diversity of these areas causing an expansion in the cultural and economic horizons of local people and producing at the same time conflicts in their interests, values and lifestyles. More specifically, the study examines the endogenous development based on the exploitation of local resources and its sustainability for future generations ${ }^{[4-9]}$. 


\section{J. Social Sci., 5(2): 80-84, 2009}

\section{MATERIALS AND METHODS}

Study area: Three municipalities of southern Peloponnese in Greece namely Koroni, Methoni and Pilos (Fig. 1) were selected for the study. These three municipalities were selected because they constitute regions of common historical heritage, big natural beauty and high environmental importance. However, during the past few years they suffer intense changes, mainly the shrinkage of the primary sector, the demographic reduction and the weakness of exploitation of "dynamic" sectors of local economy as the tourism, the small to medium-sized enterprises and the cultural and environmental heritage.

Data collection: An empirical investigation took place during April and May of 2007 and included visits to local institutions for data collection and a questionnaire survey of local residents. The questionnaires were distributed to men and women irrespectively of age, family status, income, residence and educational level. The following data on factors that may influence the social and economic development of the three municipalities of Peloponnese were collected: Family status of residents, educational level, income, role of tourism, infrastructures, transportation, participation of citizens in public affairs, treatment of groups of people like immigrants, women and youth, access of residents to information and technological progress, as well as quality and degree of environmental exploitation. The data collected were analyzed to investigate the endogenous sustainability and regional development of the municipalities under study.

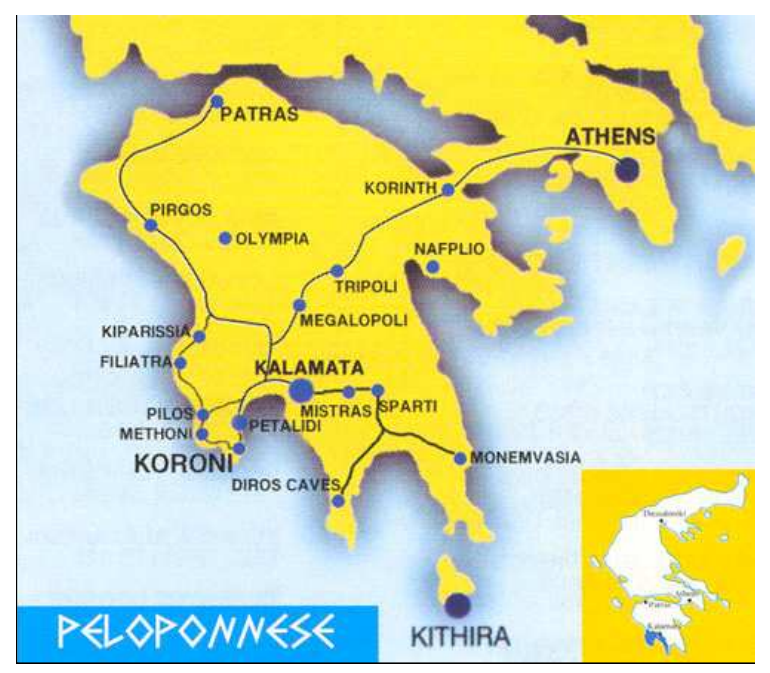

Fig. 1: Map of Peloponnese, Greece (Study areas: Pilos, Methoni, Koroni)
Statistical analysis: The data collected were analyzed by using descriptive statistics for calculating the means and standard deviations of quantitative variables and the frequencies and percentages of qualitative variables. Data elaboration and statistical analysis were performed using SPSS10, cross-tabulations were made between related responses and the chi-square $\left(\mathrm{x}^{2}\right)$ test of independence was used for statistical comparisons among them. We are reporting all significant dependencies where their p-values are $<\alpha=0.05$, our standard significant level. Finally, regression model $(\mathrm{Y}=\mathrm{a}+\mathrm{bX})$ were used to explain variations of regional development, as well as resident's responses to the questions on the subjects described above.

\section{RESULTS}

Descriptive statistical methods: The sample size of residents who participated in the questionnaire survey was a total of 120 based on 9\% of population of each one of the three municipalities. The demographic and economic characteristics of the three municipalities are as follows:

The municipallity of Koroni: Koroni is constituted mainly by four-member families (43\%), with main employment in the primary sector (19\%), but also with a wide distribution in other occupations as occupied in small, familial enterprises, craftsmen, employees (private and public) and landlords. Free lance professionals as well as university graduates belong to specialties with limited demand: agronomists, accountants and teachers. Local residents have relatively low monthly incomes of which $57 \%$ have up to $1500 €$, which they supplement with agricultural activities $(84 \%)$. They do not participate in public affairs $(72 \%)$ and they are not interested to seek information for subjects that may benefit them for opportunities to betterment their financial situation (Community programs, subsidies or seminars), but on the other hand the information offered is limited. Many residents (49\%) supplement their income with activities related to tourism such as renting of rooms (35\%), casual employment (30\%) in coffee shops, restaurants or hotels, mainly during summertime that give an opportunity for employment also to women who can work part time close to their households.

The Municipallity of Methoni: Methoni is constituted mainly by four-member and five-member families (55\%), with a higher population of men compared to women. Most of the residents are graduates of middle school (25\%) or high school (25\%) and many are active 
in the cooperatives $(41.5 \%)$ and in search of information for the betterment of their financial situation, however they can not achieve much due to the lack of basic infrastructures such as roads, water supply, sewerage and waste management. The rural sector, even as it shrinks, continues to be of big importance because it provides primary and secondary (29\%) employment to local residents, as well as additional income to families through farming. However, the opportunities for employment are low $(67 \%)$ with the result that many residents have experienced unemployment during the recent years (13\%). Moreover, discussions with the residents during the field study revealed suspicions by many of them $(65.3 \%)$ for activities of a third economy in the wider region, mainly concerning trafficking of drags.

Municipality of Pilos: The educational level of the residents is low (middle and high school 36.8\%, elementary school $24.5 \%$ ), the population of men compared to women is higher and most residents belong to families of three members and more (50\%). The location of the regional administration in the city of Pilos expands somehow the spectrum of professional activities of the residents beyond the dominating primary sector $(26.5 \%)$ and includes small to mediumsized enterprises (18.4\%), craftsmen (10.2\%), public/municipal employees $(8.2 \%)$ and freelance professionals (6.1\%). Finally, there are high expectations for the strengthening of the local economy due to tourism $(72.9 \%)$, mainly because the region of Pilos was selected for an integrated tourist infrastructure development project that is expected to attract quality tourism of high incomes. This development project involves among others the improvement of the national and provincial roads in the region.

Even though the farmland in all three areas is decreasing at the expense of residential land, the main employment is still farming (24\%). Generally, local residents who work in the public or private sector try to supplement their income with agricultural activities or tourist activities (67\%). Therefore, new enterprises are founded through private investments, which increase the local entrepreneurship (42\%).

Cross-tabulation statistical methods: Based on the statistical analysis of the responses to the questionnaire survey it was found that the quality of infrastructure (road network) was negatively related to the distance of the respondent's residence to the nearest hospital ( $\mathrm{p}$-value $=0.001<\alpha=0.05$ ), that is residents who characterized the road network of the region as bad or medium bad, they needed more than $30 \mathrm{~min}$ to reach the nearest hospital, while residents who characterized the road network as good they reported that they needed less than $30 \mathrm{~min}$ to reach the nearest hospital. Also, it was found that the more an area was economically developed the more pharmacies were in the specific area $(\mathrm{p}$-value $=0.0437<\alpha=0.05)$.

Linear regression model: A linear regression model was conducted to investigate the direct effects of local characteristics variables on sustainable development of the study area. The dependent variable was measured based on the sample's responses to a 2-point scale: yes, no to the following statement: "If your area is a sustainable area". The independent variables included the following defining factors: employment opportunities, education, income, infrastructure and exploitation of cultural heritage. Table 1 presents the results of regression model of sustainable development by various factors.

The results of regression model that was used indicated as statistically significant at a level of importance $5 \%$, the independent variables "exploitation of cultural heritage" and "infrastructures". Thus, the final regression model was formulated as follows:

Sustainable development $=9.385-0.616 *($ infrastructures $)-$ $2.673 *$ (no exploitation of cultural heritage) $-1.306 *$ (little exploitation of cultural heritage)

Table 2 shows the results of the final model of linear regression of sustainable development by the degree of exploitation of cultural heritage and the infrastructures at a level of importance $5 \%$.

Table 1: Results of linear regression model of sustainable development

\begin{tabular}{llrr}
\hline Dependent variable: Sustainable development & \multicolumn{1}{c}{$\mathrm{b}$} & $\mathrm{p}$ \\
\hline Employment opportunities & No & -0.883 & 0.075 \\
(category of report: Yes) & Limited & -0.392 & 0.263 \\
Education & High school & 0.283 & 0.406 \\
(category of report: Obligatory) & Vocational/ & -0.053 & 0.873 \\
& University & & \\
Income (category of report: Low) & Medium & -0.292 & 0.455 \\
& High & 0.066 & 0.850 \\
Exploitation of cultural heritage & No & -2.800 & $<0.001$ \\
(category of report: Yes) & Little & -1.426 & 0.001 \\
Infrastructures (0: Good, 1: Bad) & & -0.951 & 0.009 \\
\hline
\end{tabular}

Table 2: Results of linear regression model of sustainable development by the cultural heritage and the infrastructures Dependent variable: Sustainable development

\begin{tabular}{llll}
\hline Exploitation of cultural heritage & No & -2.673 & $<0.001$
\end{tabular}

$\begin{array}{llrr}\text { (category of report: Yes) } & \text { Medium } & -1.306 & 0.002 \\ \text { Infrastructures (0: Good, 1: Bad) } & & -0.616 & 0.022\end{array}$

$\begin{array}{lrr}\text { Constant } & 9.385 & <0.001\end{array}$ 
The above results indicate that: (a) Between regions with the same infrastructures that do not have or have little exploitation of cultural heritage they are expected to have on average "lower" sustainable development (at 2.7 and 1.3 units respectively) compared to regions that exploit the cultural heritage and (b) Between regions with the same exploitation of cultural heritage those that have bad infrastructures are expected to have on average "lower" viable growth (at 0.6 units) compared to regions that have good infrastructures.

\section{DISCUSSION}

Municipallity of Koroni (www.koroni.gr): Due to the proximity of Koroni to the regional capital, Kalamata, many people live in Koroni and work in Kalamata or vice versa. Also, many people of Kalamata live in Koroni during the weekends and many people of Koroni visit Kalamata and participate in its commercial and cultural life. This situation gives Koroni the sense that "it supplements" its possibilities, however it does not let Koroni to support itself on its own potency and discover its endogenous potential for development. However, in this frame, Koroni due to its proximity with the regional capital, has accesses to big scale infrastructures (airport, harbor, hospital, market, national road network), facilitating thus the lifting of the isolation from the rest of the country and abroad.

Municipallity of Methoni (www.methoni.gr): Methoni is the more flat and near to the coast area from the three examined municipalities. Therefore, it has intense growth of tourist businesses in its coastal area and faces the problem of population concentration in the coast and the shrinkage of the rural population that lives in the interior of this region. It has a small population and is somewhat removed from the regional capital, Kalamata. Methoni tries to become autonomous mainly through the growth of tourism, however it maintains certain dependences to the near administrative centre, Pilos (administrative services or health centre). Apart from the castle ruins that are a touristic attraction, Methoni has areas with various rare ecotypes worth visiting protected by nature, historical monuments, caves and forests that remain to a great degree unexploited, but also unknown to the wide public that could attract visitors. One idea that has not materialized is to establish in these areas nature observatories as well as a marine archaeological park in the region of shipwrecks that will promote environmental education.
Municipality of Pilos (www.pilos.gr): Pilos constitutes for the wider region a small administrative and commercial centre that substitute to some degree the regional capital, which is the city of Kalamata. Despite this role, Pilos remains an intensely rural region, with the same characteristics and problems of the other two municipalities described above. The mountainous morphology of the region which is connected to an old and problematic road network and downgraded infrastructures in sewerage and water supply has created as in Methoni, the double picture of the most developed, tourist beaches in concurrence with the semi deserted mountainous villages. Pilos, which is known since ancient and Modern Greek history, is a region with important ecotypes and regions protected by nature, as well as villages with characteristic architecture which could be exploited attracting quality high income tourism that would lead to the financial improvement of the local residents.

Based on the above discussion and the crosstabulation results it is very important for all three areas to develop an adequate road network in order to overcome problems of transportation for business, commerce or health.

\section{CONCLUSION}

The results of the present study indicate that the municipalities of Koroni, Methoni and Pilos have important advantages that can support sustainable development. These municipalities are mainly rural regions where the dominated production is olives and olive oil. All three regions are characterized by mild climate, common history and cultural heritage, famous beaches, tourism and small to medium-sized enterprises that are related with tourism. However, the primary sector which was based on Community subsidies for many years, today declines and can not offer a satisfactory family income, while the tourist development is up to now uncoordinated and based in family type lodgings. Thus according to the last census, the population of the three municipalities decreases because the young persons (and mostly young women) often abandon their place of origin to live in the cities due to lack of employment opportunities and in search of social-cultural interests.

All three municipalities present serious deficiencies in basic infrastructures-water supply, sewage network, electrification, road network, transportation, health, facilities of education-that impends any developments and degrades the quality of life of residents and visitors. It is very important for this area to introduce suitable policy formulation and program implementation in 
order to overcome their new problems and to have sustainable development. These policies must suggest specific constraints for tourism increase in order to avoid environmental deterioration, to promote vocational programs in order to increase employment, to encourage environmentally friendly activities such as soft tourism and organic farming and most important to create the necessary infrastructure in the area.

\section{REFERENCES}

1. Atkisson, A., 1996. Developing indicators of sustainable community: Lessons from sustainable seattle. Environ. Impact Assess. Rev., 16: 337-350. DOI: 10.1016/S0195-9255(96)00025-X

2. Azari, R. and J.B. Pick, 2005. Technology and society: Socioeconomic influences on technological sectors for United States countries. Int. J. Inform. Manage., 25: 21-37. http://cat.inist.fr/?aModele $=$ afficheN\&cpsidt $=1647$ 0573

3. Blair, H., 2000. Participation and accountability at the periphery: Democratic local governance in six countries. World Develop., 28: 21-39. http://ideas.repec.org/a/eee/wdevel/v28y2000i1p21 $-39 . \mathrm{html}$
4. Blassingame, L., 1998. Sustainable cities: Oxymoron, utopia, or inevitability? Soc. Sci. J., 35: 1-13. DOI: 10.1016/S0362-3319(98)90055-6

5. Cohen, J.H., 2001. Textile, tourism and community development. Ann. Tourism Res., 28: 378-398. DOI: $10.1016 / \mathrm{S} 0160-7383(00) 00060-8$

6. MacDonald, R. and L. Jolliffe, 2003. Cultural rural tourism, evidence from Canada. Ann. Tourism Res., 30: 307-322. DOI: 10.1016/S01607383(02)00061-0

8. Ranney, D.C. and John J. Betancur, 1992. Laborforce-based development: A community oriented approach to targeting job training and industrial development. Econ. Develop. Q., 6: 283-296. DOI: 10.1177/089124249200600305

9. Wolman, H. and D. Spitzley, 1996. The politics of local economic development. Econ. Develop. Q., 10: 115-150. DOI: 10.1177/089124249601000201 